\title{
Research on Profit Distribution Mechanism for the Alliance of Industrial Park Wastes
}

\author{
Kailun $\mathrm{He}^{1, \mathrm{a}}$, Xiuli Bao ${ }^{2, \mathrm{~b}}$ and Huilong Sun ${ }^{3, \mathrm{c}}$ \\ ${ }^{1}$ School of Business Administration, Chongqing University of Technology, Chongqing ,China \\ ${ }^{2}$ School of Business Administration, Chongqing University of Technology, Chongqing ,China \\ ${ }^{3}$ School of Business Administration, Chongqing University of Technology, Chongqing ,China \\ ahekailun@cqut.edu.cn, b1844644260@qq.com, '853683630@qq.com
}

\begin{abstract}
Keywords: Profit distribution; Cooperative games; Wastes disposal alliance
Abstract. This paper mainly consider company's implementation capacity, alliance profit and other factors with the certainty equivalence revenue maximization as the goal of the game, under the condition of meeting the cooperative game rationality to construct the cooperative profit distribution model of wastes disposal alliance and get profit distribution mechanism. Finally, industrial park wastes disposal in Chongqing as an example to verify scientific validation and the applicability of the proposed model and method.
\end{abstract}

\section{Introduction}

Industrial park wastes disposal is the most important work in urban pollution control and environmental protection. Park wastes disposal can enhance the competitiveness of enterprises, and achieve integration of resources and effective management. Wastes disposal alliance development of the key is to establish a reasonable profit distribution mechanism. The scholars mainly adopted Shapley value method, core method, and game model to solve it. Researchers used Shapley value method more and improved continuously [1-4]. Core method mainly used for the empirical analysis to build the alliance profit distribution model [5-6]. The dynamic game model is used to solve alliance profit allocation mechanism [7] and to conclude alliance optimal profit distribution coefficient and optimal effort level [8-9].

Project group conducted special investigations to Chongqing characteristic industrial park wastes disposal between May 2012 and March 2013. This paper based on the actual investigation data to analysis the wastes disposal alliance's feature and build alliance profit distribution model, used cooperative game and non-cooperative game to reverse calculate, obtained scientific and reasonable profit distribution mechanism, provided practical theory basis for park wastes management.

\section{The construction of profit distribution model for the alliance of industrial park wastes}

Industrial Park wastes disposal alliance composes mainly of providing wastes disposal services for a number of business license enterprises, it has the general characteristics of strategic alliance.

Assuming that the Industrial Park wastes disposal alliance is made up of $N$ enterprises $(i=1,2, \ldots, n)$, i represents the i-th enterprises, 1 refers to the leader; other $\mathrm{N}-1$ enterprises are leagues.

Hypothesis 1: Alliance and enterprise profit and the level of effort are linear relationship. $\mathrm{R}$ represents alliance profit, $D_{i}$ represents earnings that the independent enterprise engaged in wastes disposal to obtain under the non-aligned situation, the enterprise pay the same level of effort: $R \geq \sum_{i=1}^{n} D_{i}$. According to Holmstrom and Milgrom parametric expansion model [10], $D_{i}$ and the level of effort are linear relationship: $D_{i}=v_{i} a_{i}+\varepsilon_{i}\left(\varepsilon_{i}\right.$ means normal distribution random variables with mean of 0 , and reflects output affected by changes in the market, with uncertainty. $a_{i}$ represents enterprises level of effort, it is equal to the ratio of the enterprise actual effort and ideal 
hard indicators, $0<a_{i} \leq 1$. Enterprises can choose the level of effort indicators including the total input, total output or the total recycling capacity etc; Acute effort index is the real data obtained by enterprises in business, and the ideal index is data the enterprises can realize under the full ability worked. $v_{i}$ represents output coefficient of the i-th independent enterprise, it is the enterprise unit of effort outputs, and can be used to measure corporate profitability. If $v_{i}$ is measured by currency, $v_{i}$ is the level of effort's profit coefficient. $v_{i}$ reflects the enterprise wastes management implementation ability; The bigger the $v_{i}$ is, the greater the enterprise implement ability is. The enterprise alliance profit $\mathrm{R}$ and enterprise alliance effort are linear relationship: $R=\sum_{i=1}^{n}\left(v_{i} a_{i}\right)+R^{0}+\varepsilon$.it is the normal distribution of random variable with mean of 0 and variance $\sigma^{2}, R^{0}$ represents alliance profit increment, $R^{0}>0$ represents the overall revenues increase. Alliance expects earnings or average earnings: $E(R)=\sum_{i=1}^{n}\left(v_{i} a_{i}\right)+R^{0}$.

Hypothesis 2: Enterprise's cost and the level of effort are quadratic function relation. Wastes disposal cost is composed of sunk cost and the cost of innovation, sunk costs are a relatively fixed cost, it has nothing to do with the degree of effort; the cost of innovation increase along with the increase of the degree of effort. $\phi_{i}$ is the $\mathrm{i}$-th enterprise innovation cost coefficient, $\phi_{i}>0 ; \phi_{i}$ depends on the enterprise implementation capacity, the greater the value shows, the more enterprises cost is and the weaker the enterprises implement ability is on the same level of effort. Enterprise innovation cost can be expressed as a quadratic function of the effort level of the enterprise, $0.5 \phi_{i} a_{i}^{2}$. if $C_{i}$ is the total cost of the $\mathrm{i}$-th enterprise, $I_{i}$ is sunk cost, then, $C_{i}=I_{i}+0.5 \phi_{i} a_{i}^{2},(\mathrm{i}=1,2, \ldots \mathrm{N})$.

Hypothesis 3: All alliance profit is allocated to enterprises. $s_{i}$ represents the coefficient of the i-th enterprise profit distribution, $\sum_{i=1}^{n} s_{i}=1,0<s_{i} \leq 1(\mathrm{i}=1,2, \ldots \mathrm{N}) . E(R)=\sum_{i=1}^{N} R_{i}, R_{i}=s_{i} E(R), R_{i}$ represents the $\mathrm{i}$-th enterprise profit in the alliance. Leader according to the linear relationship paid to members $T /(N-1)+s_{i} R(i \neq 1), \mathrm{T}$ is a fixed payment, associates with sunk costs, has nothing to do with the level of effort, it is both leader cost and members benefits. $s_{1} R$ represents leader profit , $T /(N-1)+s_{i} R$ represents members earning.

The alliance of profit allocation decisions are two-stage decision-making process, including the cooperative game and non-cooperative game. Optimal benefit allocation decisions should meet three conditions of rationality: $\AA$ Individual rationality conditions, players benefit can't less than nonparticipants in the alliance ; Ç The overall rationality condition, the alliance benefit allocated to all participants; É Alliance rationality conditions, the alliance's overall profit is more than non- alliance's.

Enterprises are generally risk-averse, their utility function $u$ has absolute risk aversion characteristics: $u(w)=-e^{\rho w}, \rho=-u^{\prime \prime}(w) / u^{\prime}(w) \geq 0, \rho$ is the arrow - para absolute risk aversion coefficient, indicates the extent to which enterprises are afraid of the risk; $w$ is the actual monetary profit. Alliance profit: $R_{i}=s_{i} R$, the variance: $\mathrm{s}_{\mathrm{i}}^{2} \sigma^{2}$. According to Arrow-Prat theory, enterprise risk cost $=0.5 \times$ the absolute risk aversion $\times$ the variance of profit, the i-th enterprise risk cost: $0.5 \rho_{i} \mathrm{~s}_{\mathrm{i}}^{2} \sigma^{2}$,

$\rho_{i}$ represents the i-th enterprise absolute risk aversion coefficient. Enterprise risk cost and the profit coefficient is proportional, the greater the profit's share is, the bigger the risk is, reflecting the "profit sharing and risk-sharing" principles of alliance cooperation. 
Alliance profit of cooperative game decision-making: $R=\sum_{i=1}^{N}\left(v_{i} a_{i}\right)+R^{0}+\varepsilon$, the actual alliance monetary profit: $\sum_{i=1}^{N}\left(v_{i} a_{i}\right)+R^{0}+\varepsilon-\sum_{i=1}^{N} C_{i}$, expected monetary profit: $\sum_{i=1}^{N}\left(v_{i} a_{i}\right)+R^{0}-\sum_{i=1}^{N} C_{i}$, so the union of certainty equivalent profit: $\sum_{i=1}^{N}\left(v_{i} a_{i}\right)+R^{0}-\sum_{i=1}^{N} C_{i}-0.5 \sum_{i=1}^{N} p_{i} s_{i}^{2} \sigma^{2}$. Non-cooperative game enterprise alliance based on their own interests determined the degree of effort, the leader enterprise actual monetary profit and deterministic equivalent profit: $s_{1} E(R)-T-C_{1}, s_{1} E(R)-T-C_{1}-0.5 \rho_{1} s_{1}^{2} \sigma^{2}$. Similarly, alliance members actual monetary profit: $T /(N-1)+s_{i} E(R)-C_{i}$ and its deterministic equivalent profit: $T /(N-1)+s_{i} E(R)-C_{i}-0.5 \rho_{i} \mathrm{~s}_{\mathrm{i}}^{2} \sigma^{2}$.

According to the principle of cooperation game and alliance revenue allocation mechanism, $\mathrm{CE}$ and $C E_{i}(\mathrm{i}=1$ represents the leader $)$ mean wastes disposal alliance and members determine the revenue equivalence respectively. Bring the enterprise cost function and expected benefit of the league into the alliance and enterprise certainty equivalence revenue calculation formula, obtain:

$$
\begin{gathered}
C E=\sum_{i=1}^{N}\left(v_{i} a_{i}\right)+R^{0}-\sum_{i=1}^{N}\left(I_{i}+0.5 \phi_{i} a_{i}^{2}\right)-0.5 \sum_{\mathrm{i}=1}^{\mathrm{N}} \rho_{\mathrm{i}} s_{i}^{2} \sigma^{2} \\
C E_{1}=s_{1}\left[\sum_{i=1}^{N}\left(v_{i} a_{i}\right)+R^{0}\right]-T-I_{1}-0.5 \phi_{1} a_{1}^{2}-0.5 \rho_{1} \mathrm{~s}_{1}^{2} \sigma^{2} \\
C E_{i}=T /(N-1)+s_{i}\left[\sum_{i=1}^{N}\left(v_{i} a_{i}\right)+R^{0}\right]-I_{i}-0.5 \phi_{i} a_{i}^{2}-0.5 \rho_{i} s_{i}^{2} \sigma^{2}
\end{gathered}
$$

Eq. (1), (2), (3) $\left(R^{0}>0, \sum_{i=1}^{N} s_{i}=1\right)$ meet the alliance rationality condition and the overall rationality condition, but lack the individual rationality condition $R_{i}>E\left(D_{i}\right)$. Bring $R_{i}=s_{i} E(R)$ and $E\left(D_{i}\right)=v_{i} a_{i}$ into individual rationality conditions can obtain:

$$
s_{i}\left[\sum_{i=1}^{N}\left(v_{i} a_{i}\right)+R^{0}\right] \geq v_{i} a_{i}
$$

Eq. (1), (2), (3), (4) constitute alliance profit allocation model.

\section{Analysis on the profit distribution mechanism}

Considering profit distribution game decision inverse process. Suppose the leader and members know both sides of the profit distribution coefficient. According to (2) and (3) partial derivative of $a_{i}$, let $\partial C E_{1} / \partial a_{1}=0, \partial C E_{\mathrm{i}} / \partial a_{i}=0$ can obtain: $\partial C E_{1} / \partial a_{1}=s_{1} v_{1}-\phi_{1} a_{1}=0, \partial C E_{\mathrm{i}} / \partial a_{i}=s_{i} v_{i}-\phi_{i} a_{i}=0$.By solving the equation, the degree of enterprise effort in game equilibrium:

$$
a_{i}=s_{i} v_{i} / \phi_{i}(i=1,2, \ldots, N)
$$

The degree of effort is proportional to the output coefficient and the profit distribution coefficient, and is inversely proportional to the cost of innovation. Eq. (5) shows that the implementation of strong ability and high profit distribution of enterprises are willing to increase investment to improve the level of output.

According to the ep.(1) and $\sum_{i=1}^{N} s_{i}=1$ to set a new function $C E F\left(s_{i}\right)$ in order to solve the optimal value problem with the condition:

$$
C E F=\sum_{i=1}^{N}\left(v_{i} a_{i}\right)+R^{0}-\sum_{i=1}^{N}\left(I_{i}+0.5 \phi_{i} a_{i}^{2}\right)-0.5 \sum_{\mathrm{i}=1}^{\mathrm{N}} \rho_{\mathrm{i}} s_{i}^{2} \sigma^{2}+\lambda\left(1-\sum_{i=1}^{N} s_{i}\right) .
$$

Bring eq.(5) into eq.(6), let $\partial C E F / \partial s_{i}=0, \partial C E F / \partial \lambda=0$, then calculate: 


$$
\begin{aligned}
& v_{i}^{2} s_{i}+\rho_{i} \phi_{i} \sigma^{2} s_{i}=v_{i}^{2}-\phi_{i} \lambda \\
& \sum_{i=1}^{N} s_{i}=1
\end{aligned}
$$

Solving by the formula (7), (8) consisting of simultaneous equations to obtain:

$$
\begin{aligned}
& \lambda=\left\{\sum_{i=1}^{N}\left[\frac{v_{i}^{2}}{\left(v_{i}^{2}+\rho_{i} \phi_{i} \sigma^{2}\right)}\right]-1\right\} / \sum_{i=1}^{N}\left[\frac{\phi_{i}}{\left(v_{i}^{2}+\rho_{i} \phi_{i} \sigma^{2}\right)}\right] \\
& \mathrm{s}_{\mathrm{i}}^{*}=\left(v_{i}^{2}-\phi_{i} \lambda\right) /\left(v_{i}^{2}+\rho_{i} \phi_{i} \sigma^{2}\right) \quad(\mathrm{i}=1,2, \ldots, N)
\end{aligned}
$$

The above equations indicate that the $\lambda$ coefficient depends on the various parameters of the alliance enterprise, but for specific alliance, it is a constant. $s_{i}^{*}$ is seeking the optimal distribution coefficient, which shows that the enterprise profit distribution coefficient decided enterprise output coefficient $v_{i}$, innovation cost coefficient $\phi_{i}$ and risk aversion coefficient $\rho_{i}$. The stronger the ability of enterprises implement is(the bigger $v_{i}$ is, the smaller $\phi_{i}$ is ), the larger enterprise profit distribution coefficient is ; the more conservative enterprises are (the bigger $\rho_{i}$ is), the higher the risk cost is, the smaller enterprises profit distribution coefficient is .

Bring eq.(10) into (5) to get the optimal the level of effort:

$$
a_{\mathrm{i}}^{*}=\left(v_{i}^{3}-v_{i} \phi_{i} \lambda\right) /\left(\phi_{i} v_{i}^{2}+\rho_{i} \phi_{i}^{2} \sigma^{2}\right)(\mathrm{i}=1,2, \ldots, N)
$$

Eq. (10) and eq.(11) institute a combination of decision-making $\left(s_{i}^{*}, a_{i}^{*}\right)$ show that coalition optimal allocation mechanism and $v_{i}, \phi_{i}, \rho_{i}$ and $\sigma^{2}$ are related, has nothing to do with $\mathrm{T}, \mathrm{I}_{\mathrm{i}}$ and $\mathrm{R}^{0}$; the stronger enterprises implementation and risk awareness are (the greater $v_{i}$ is, the smaller $\phi_{i}$ and $\rho_{i}$ are), the bigger enterprises pay the effort and the share of profit distribution are.

$\left(s_{i}^{*}, a_{i}^{*}\right)$ must satisfy (4), bring eq.(5) into eq.(4): $\sum_{i=1}^{N}\left(v_{i} a_{i}\right)+R^{0} \geq v_{i}^{2} / \phi_{i}$. The left is alliance expected return $\mathrm{E}(R)$, the alliance expected profit must satisfy the equation: $E(R) \geq v_{i}^{2} / \phi_{i}$ $(\mathrm{i}=1,2 \ldots \mathrm{N})$. Bring the optimal coefficients $s_{i}^{*}$ into the relationship formula:

$$
\mathrm{R}^{0} \geq \frac{\mathrm{v}_{\mathrm{i}}^{2}}{\phi_{i}}-\sum_{\mathrm{i}=1}^{\mathrm{N}}\left(\frac{v_{i}^{4}-v_{i}^{2} \phi_{i} \lambda}{v_{i}^{2} \phi_{i}+\rho_{i} \phi_{i}^{2} \sigma^{2}}\right)
$$

Eq. (12) shows that the enterprise alliance additional revenue must achieve a certain level, the league member enterprises of individual rationality conditions can be met. This level is decided by eq.(12). $\left(s_{i}^{*} 、 a_{i}^{*}\right)$ became the alliance optimal profit distribution mechanism.

\section{Case analysis}

An industrial park is located in Chongqing urban area, has the large-scale automobile and motorcycle and car accessories industry group, industrial output value is more than 50 billion Yuan in 2014. Take Chongqing characteristic industrial park A,B, C three licensing enterprises as an example, A enterprise can recycle disposal 1200 tons of oil, B and C enterprises process 800 tons respectively, they can satisfy the main 2-3 zone of waste oil disposal requirements. Suppose A enterprise as the leader $(i=1)$, $\mathrm{B}$ and $\mathrm{C}$ as leagues $(\mathrm{i}=2,3)$, It is expected to alliance additional revenue $\mathrm{R}^{0}$ will add $\mathrm{RMB} 120000$ every year, alliance benefit variance is RMB 1.4391 million every year.

The leader paid to members fixed payment is $\mathrm{T}=40000 \mathrm{yuan}$ every year, each member was 20000yuan. The level of effort: $0<a_{i} \leq 100$.According to the enterprise data to calculate $V_{i}, \phi_{i}$ and $I_{i} \cdot \rho_{i}$ references to American finance and investment industry convention, the value is limited to 2-6, and the specific value of each enterprise is determined by the expert experience. The alliance profit distribution model parameters and data are shown in Table 1 . 


\begin{tabular}{|c|c|c|c|}
\hline $\begin{array}{c}\text { Alliance enterprise } \\
(N=3)\end{array}$ & $\mathrm{A}$ & $\mathrm{B}$ & $\mathrm{C}$ \\
\hline $\mathrm{v}_{i}$ & 0.05 & 0.034 & 0.034 \\
\hline$\phi_{i}$ & 0.0007 & 0.0003 & 0.0003 \\
\hline$\rho_{i}$ & 0.04 & 0.06 & 0.06 \\
\hline$I_{i}$ & 0.55 & 0.45 & 0.48 \\
\hline
\end{tabular}

Table 1 Parameters of oil disposal alliance (unit: million Yuan)

Take the above data into formula (1) to (11), by calculating and analyzing to obtain the park disposal alliance profit distribution model and decisions:[ $\left.\left(s_{i}^{*} 、 a_{i}^{*}\right)\right]=[(0.3829,27.3843)$,

$(0.3086,34.9704),(0.3086,34.9704)]$.Take enterprise alliance data into the formula (12), get a vector $[-17.3970,10.7934,10.7934]$, due to union added revenue $R^{0}=12>$ [-0.173970,0.107934,0.107934] (million Yuan), the union operation satisfy individual rationality condition, so the decision $\left(s_{i}^{*} 、 a_{i}^{*}\right)$ is the league's optimal allocation mechanism.

\section{Analysis of the operation of the Alliance}

According to the allocation model, the coalition expected benefit $=5 a_{1}+3.4 a_{2}+3.4 a_{3}+12$, total cost $=148+0.035 a_{1}^{2}+0.015 a_{2}^{2}+0.015 a_{3}^{2}$, risk cost $=287.82 s_{1}^{2}+431.73 s_{2}^{2}+431.73 s_{3}^{2}, \quad$ take formula $\left(s_{i}^{*} 、 a_{i}^{*}\right)$ data into the calculation equation, league expected revenue and total cost and risk cost respectively are 3.865,2.109,1.244million Yuan every year and its deterministic equivalent profit 3.865-2.109-1.244=0.512 million Yuan every year.

Calculation results show that leader enterprise have large output coefficient, small risk aversion coefficient, big recycling disposal capacity, the implementation ability occupies a larger share of the proceeds $38.29 \%$ under the alliance operation optimal allocation mechanism; all profit deduct annual fixed payment to league enterprises 0.04 million Yuan and obtain the equivalent maximum benefit 0.206 million Yuan every year, it is higher than B and C . Leader's optimal level of effort is 328.6 tons every year, the other two enterprises are 279.8 tons every year, Alliance disposal wastes oil 888.2 tons, obtain the expected revenue and deterministic equivalent profit respectively 3.865 and 0.512 million Yuan every year.

\section{Conclusions}

Industrial Park wastes disposal alliance revenue allocation mechanism only is related with enterprise output coefficient, coefficient of innovation cost, risk aversion coefficient and the union of the variance of return, has nothing to do with a fixed payment, fixed costs . Strong implementation capability, innovation spirit and large recovery processing enterprises occupy a larger share of the profit distribution in the league.

Alliance additional profit must reach a certain level to establish the optimal allocation mechanism, and additional revenue mainly comes from alliance enterprises learning. In this paper, the research is weak on the alliance learning and the benefits problems, so they need further study. 


\section{Acknowledgments}

This work was financially supported by the Shanghai Natural Science Foundation (0666666), Innovation Program of Shanghai Municipal Education Commission (060000) and Shanghai Leading Academic Discipline Project of Shanghai Municipal Education Commission (0555555).

\section{References}

[1] Lilin Diao , Guilong,Zhi Xu. The Profit Allocation of Alliances Based on the Multi-weighted Shapley Value. Industrial Engineering and Management,Vol. 16(4) (2011), p.79-91 .(In Chinese)

[2] Xueyuan Wang, Zhilin Wang . The Distribution of R\&D Alliance Output. Research Management, Vol.32 (3)(2011), p.29-34.(In Chinese)

[3] Xiang Wang, Weidong Meng, Guodong Wu. The Profit Distribution of R \& D Alliance Under the Uncertain Conditions . Systems Engineering, Vol.32 (7) (2014),p.63-68.(In Chinese)

[4] Jinghua Wan. Study on Logistics League Benefit Distribution Based on Shapley Value Method . Logistics Technology, Vol.32 (L1)(2013),p. 306-308.(In Chinese)

[5]Peng Liang, Jiang Li. Research on Agricultural Products Supply Chain Alliance Profit Mechanism based on The Shapley value. Business Research, (2013),p. 191-194.(In Chinese)

[6] Alf Kimms, Demet Cetiner. Approximate Nucleolus-based Revenue Sharing in Airline Alliance. European Journal of Operational Research, (2012),p.510-521.

[7] Arantza Estévez-Fernández,Hans Reijnierse. On the Core of Cost-revenue Games: Minimum cost spanning tree games with revenues. European Journal of Operational Research, p.606-616.

[8] Yuki Kumoi,Nobuo Matsubayashi.Vertical Integration With Endogenous Contract Leadership: Stability and Fair Profit Allocation. European Journal of Operational Research,( 2014),p.221-23 2. (In Chinese)

[9] Chengxian Yu, Dongqiang Guo. Knowledge profit Distribution Contract Design of Knowledge Alliance. library and information science,Vol.55 (22)(2011) ,p.114-117.(In Chinese)

[10]Qiang Lin, Wencong Sun, Yanli Hao. Modeling and Analysis of Profit Allocation in Logistics Dynamic Alliance by Considering Risk, Contribution and Time Effectiveness. industrial engineering, Vol.13 (2)(2012),p. 9-14.

[11] Weiying Zhang. Game Theory and Information Economics. Shanghai people's Publications, (2004),p.256 - 260.(In Chinese) 